\title{
Kirchliche Filmpreise 2006
}

Aufgeführt ist im folgenden eine Auswahl der Preise von Jurys der kirchlichen Filmorganisationen SIGNIS (katholisch) und INTERFILM (evangelisch), die im Jahre 2006 auf wichtigen internationalen Filmfestivals vergeben wurden.

\section{Internationale Filmfestspiele Berlin (9. bis 19. Februar 2006)}

Die Ökumenische Jury vergibt in Berlin Preise in den Programmsektionen Internationaler Wettbewerb, Panorama und Internationales Forum des Jungen Films.

\section{Internationaler Wettbewerb}

Preis der Ökumenischen Jury:

„Grbavica“ (dt. Titel: „Esmas Geheimnis“)

Österreich/Bosnien und Herzegowina/Deutschland 2005

Regie: Jasmila Zbanic

\section{Begründung:}

Der Film erhält den Preis „für seine einfühlende und vorurteilsfreie Erzählweise, für seine Darstellung von menschlicher Verletzbarkeit und der Kraft der Liebe, Hass und Gewalt zu überwinden, für seine sensible Darstellung der universalen Problematik der Versöhnung“.

\section{Programmsektion Panorama}

Preis der Ökumenischen Jury:

„Komornik“ (Der Gerichtsvollzieher)

Polen 2005

Regie: Feliks Falk

Begrüindung:

Der Film erhält den Preis ,für ein genaues Portrait des aktuellen politischen Wandels in Polen, das zugleich eine ethisch eindringliche Geschichte über die universale Problematik der Korruption erzählt, für die 
hohe künstlerische Qualität der Darstellung von Gerechtigkeit und Menschenwürde“.

Programmsektion Internationales Forum des Jungen Films

Preis der Ökumenischen Jury:

"Conversations on a Sunday Afternoon"

Südafrika 2005

Regie: Khalo Matabane

Begründung:

Der Film erhält den Preis „für eine formal gelungene und inhaltlich eindrucksvolle Dokumentation der Situation von Kriegsflüchtlingen aus aller Welt, die in Johannisburg leben“.

\section{Internationale Kurzfilmtage Oberhausen (4. bis 9. Mai 2006)}

Preis der Ökumenischen Jury:

„Me First" (Ich zuerst)

Kenia 2005

Regie: William Owusu

Begründung:

Ein Mann reflektiert einfühlsam seine zerbrochene Beziehung, überwindet empathisch seine Selbstzweifel und geht schließlich seinen Weg. Beeindruckend ist dabei die Übertragung seiner Befindlichkeit in die Bildsprache. Nicht zuletzt hat der Film auch darin eine besondere Qualität, dass er ein Bild aus Afrika vermittelt, das wenig bekannt ist.

Lobende Erwähnung:

„Civil Status“ (Personenstand)

Russland 2005

Regie: Alina Rudnitskaya

Begründung:

In einer Behörde fängt die Regisseurin menschliche Reaktionen bei Lebenseinschnitten wie Hochzeit, Scheidung, Geburt und Tod ein. Gestik und Mimik der Beteiligten durchbrechen nicht nur den bürokratischen Rahmen, sondern auch den dokumentarischen Charakter des Films. Gefühle beugen sich nicht dem Verwaltungsapparat. 
Lobende Erwähnung:

„A Moment of Love“ (Ein Augenblick der Liebe)

Malaysia 2005

Regie: James Lee

Begründung:

„A Moment of Love“ ist ein Film über eine zerbrechende Partnerschaft, der dem Publikum viel Raum gibt, sich in die Gedanken der Protagonisten einzufühlen. In ausdrucksvollen Bildern und mit wenigen Dialogen hält er die Zuschauer in Bann, ohne eine endgültige Lösung vorzugeben.

\section{Internationale Filmfestspiele Cannes (17. bis 28. Mai 2006)}

Preis der Ökumenischen Jury:

„Babel“

Mexiko 2006

Regie: Alejandro Gonzáles Iñărritu

Begründung:

Unsere Welt beruht auf einer Kommunikation, die universell, umfassend und unmittelbar zu sein scheint. Aber in Wirklichkeit handelt es sich dabei um eine Illusion, die Vorurteile, Angst und Einsamkeit gegenüber dem „anderen“ (Personen, Kulturen, Völkern, Geschlechtern, Generationen...) nährt. „Babel“ zeigt, dass eine wirkliche Beziehung nur dann möglich ist, wenn man darauf verzichtet, alles meistern zu wollen und sich gegenseitig mit seinen Stärken und Schwächen anerkennt.

Lobende Erwähnung:

„Z Odzysku“ (Second Hand)

Polen 2006

Regie: Slavomir Fabicki

Begründung:

Die Geschichte des Films spielt in einer Gesellschaft, in der Geld und Gewalt eine unwiderstehliche Anziehungskraft ausüben. Sie zeigt, dass das Glück sich nicht auf diese Weise finden lässt. Als der Held am Ende ausser seiner Würde alles verloren hat, findet er den Mut, sein Leben aufs Spiel zu setzen, um die wiederzufinden, die ihn lieben. 


\section{Internationales Filmfestival Locarno (2. bis 12. August 2006)}

Preis der Ökumenischen Jury:

"Agua“ (Wasser)

Argentinien/ Frankreich 2006

Regie: Verónica Chen

Begründung:

Der Film erhält den Preis für „die künstlerische Qualität und die Universalität der Geschichte von ,Agua'. Der Rhythmus der Schwimmbewegungen und die Omnipräsenz des Wassers unterlegen den Film mit einer meditativen Dimension. Hier finden zwei Männer verschiedenen Alters zu sich selbst. Der Film ermutigt zum Verzicht auf das Gewinnen um jeden Preis und zu Zivilcourage im Alltag.“

Lobende Erwähnung:

„Le dernier des fous“ (Der letzte Verrückte)

Frankreich/Belgien 2006

Regie: Laurent Achard

Begründung:

Mit seiner radikalen Vision denunziert der Regisseur die totale Abwesenheit von Hoffnung und Liebe.

\section{Internationales Filmfestival Venedig (30. August bis 9. September 2006)}

Preis der internationalen katholischen Medienorganisation SIGNIS:

„Nuovomondo“ (Neue Welt)

Italien/Frankreich 2005

Regie: Emanuele Crialese

Begründung:

„Nuovomondo“ macht die historischen Ereignisse der italienischen Emigration zu Beginn des 20 Jahrhunderts gegenwärtig und präsentiert Emigration als eine Metapher für eine gleichermaßen unbekannte wie unerwartete innere Reise vom ländlichen Süditalien zur modernen Welt Nordamerikas. Es gelingt dem Film, das Bewusstsein des Publikums für das globale Phänomen von Migrationsbewegungen zu wecken, für die Menschen in der westlichen Welt eine Erinnerung an die Ursprünge ihres gegenwärtigen Wohlstands. 
Lobende Erwähnung:

„Daratt"

Tschad/ Frankreich/ Belgien/ Österreich 2006

Regie: Mahamat-Salen Haroun

Begründung:

In den Nachwehen des langjährigen Bürgerkriegs im Tschad lernt eine junger Mann, der auf einem Rachefeldzug ist, zu vergeben. Der Film betont sowohl die Schwierigkeit wie auch die Notwendigkeit der Aussöhnung und benutzt das Backen - und das Brechen - des Brotes als machtvolles Symbol des Lebens und des Lebensunterhalts.

Lobende Erwähnung:

„Nue propriété“ (Private Property)

Belgien/ Frankreich 2006

Regie: Joachim Lafosse

Begriündung:

„Nue Propriété" entwirft ein Porträt einer Familienkrise und konzentriert sich dabei auf die universale Dynamik von Kommunikationsunfähigkeit, Mangel an Verantwortung und die bloße Funktionalität von Beziehungen, Konsequenzen eines wachsenden Individualismus in der westlichen Gesellschaft. Dies führt schließlich zu einer Tragödie. Der Film bietet keine Lösung an sondern provoziert einen heilsamen Schock, der die Zuschauer zum Nachdenken zwingt.

\section{Internationales Leipziger Festival für Dokumentar- und Animationsfilm (30. Oktober bis 5. November 2006)}

Preis der Ökumenischen Jury:

"Forever"

Niederlande 2006

Regie: Heddy Honigmann

Begründung:

Der in hoher filmischer Qualität vorgelegte Film begegnet mit Geduld und Respekt ganz unterschiedlichen Menschen, die alle auf dem Pariser Friedhof Pére Lachaise anzutreffen sind. Heddy Honigmann verbindet das Tote mit dem Lebendigen, in dem sie mit Hilfe der Kunst das Unvergängliche zu zeigen vermag. 


\section{Festival des osteuropäischen Films in Cottbus (14. bis 18. November 2006)}

Preis der Ökumenischen Jury:

„Indián a sestřička“ (Der Indianer und die Krankenschwester)

Tschechien 2006

Regie: Dan Wlodarczyk

Begründung:

Dramaturgisch raffiniert verschränkt der Drehbuchautor Jan Stehlik die Lebenswelten der Tschechen und der Roma, wobei erstere in ihrer Freizeit das Leben von Prärieindianern nachspielen, ohne Verständnis für die fremde Kultur zu entwickeln. In diesen Horizont eingebettet ist die Liebesgeschichte zwischen dem Tschechen Franta und der Roma Marie. Glaubwürdig und nachvollziehbar setzt der Regisseur die zwischen den Ethnien und besonders die in ihnen aufbrechenden Spannungen und Konflikte in Szene. Er führt uns damit zu der Einsicht, dass ein Miteinander die Menschen manchmal überfordert: Ein gewaltfreies Nebeneinander ist schon nicht wenig. Durch seinen Realitätssinn weist „Der Indianer und die Krankenschwester" Perspektiven auf für einen Weg, der von einem Nebeneinander zu einem Miteinander führen könnte.

\section{Internationales Filmfestival Mannheim-Heidelberg (16. bis 25. November 2006)}

Preis der Ökumenischen Jury:

„Trešeta“ (Die Kartenspieler - Geschichte einer Insel)

Kroatien 2006

Regie: Dražen Žarkovic und Pavo Marinkovic

Begründung:

Mit kunstvollen Bildern, einem starken Ensemble und feinem Humor erzählen die Regisseure in einer Filmparabel vom engagierten Kampf einer kleinen Gemeinschaft von Inselbewohnern gegen das drohende Aussterben. Das titelgebende Kartenspiel dient dieser atmosphärisch dichten Tragikomödie als Symbol für die Notwendigkeit immerwährender Hoffnung. 